\title{
BOUNDS FOR THE WEIGHTED GINI MEAN DIFFERENCE OF AN EMPIRICAL DISTRIBUTION
}

\author{
Yu MiaO, Li Ge And Ang PENG
}

Abstract. In the paper, we obtain various bounds for more general weighted Gini mean difference of an empirical distribution, which extend the results of Cerone and Dragomir in [2].

Mathematics subject classification (2010): 60E15, 26D15, 62E10.

Keywords and phrases: Gini mean difference, empirical distribution.

\section{REFERENCES}

[1] P. Cerone, S. S. Dragomir, Bounds for the Gini mean difference of an empirical distribution, Appl. Math. Lett. 19 (2006) 283-293.

[2] P. Cerone, S. S. Dragomir, Bounds for the $r$-weighted Gini mean difference of an empirical distribution, Math. Comput. Modelling 49 (2009) 180-188.

[3] G. M. GiongI, Bibliographic portrait of the Gini concentration ratio, Metron 48 (1990) 183-221.

[4] G. M. Giongi, Il rapporto di concentrazione di Gini, Libreria Editrice Ticci, Siena, 1992.

[5] G. A. Koshevoy, K. Mosler, Multivariate Gini indices, J. Multivariate Anal. 60 (1997) 252-276.

[6] F. NyGÅRD, A. SAndström, Measuring Income Inequality, Almqvist and Wiksell, Stockholm, 1981. 